\title{
UM OLHAR FEMININO SOBRE A MESTRIA E A PARTICIPAÇÃO DA MULHER NA CAPOEIRA DA GRANDE FLORIANÓPOLIS
}

Recebido em: 28/12/2020

Aprovado em: 18/02/2021

Licença:@) (1) @

Samara Escobar Martins ${ }^{1}$

Maria Eduarda Tomaz Luiz ${ }^{2}$

Universidade Federal de Santa Catarina (UFSC)

Florianópolis - SC - Brasil

Wihanna de Castro Cardozo Franzoni ${ }^{3}$

Universidade do Estado de Santa Catarina (UESC)

Florianópolis - SC - Brasil

Lais Mendes Tavares ${ }^{4}$

Universidade Federal de Santa Catarina (UFSC)

Florianópolis - SC - Brasil

Alcyane Marinho ${ }^{5}$

Universidade do Estado de Santa Catarina (UESC)

Universidade Federal de Santa Catarina (UFSC)

Florianópolis - SC - Brasil

RESUMO: A capoeira situa-se em um espaço sociocultural, não estando livre de apresentar em sua prática mazelas sociais e culturais desse meio, como o machismo.

\footnotetext{
${ }^{1}$ Mestranda do Programa de Pós-graduação em Educação Física (PPGEF) da Universidade Federal de Santa Catarina (UFSC), com bolsa da Fundação de Amparo à Pesquisa e Inovação do Estado de Santa Catarina (FAPESC). Membra do Laboratório de Pesquisa em Lazer e Atividade Física (LAPLAF/CEFID/UDESC/CNPq).

${ }^{2}$ Mestranda do Programa de Pós-graduação em Educação Física (PPGEF) da Universidade Federal de Santa Catarina (UFSC), com bolsa da Fundação de Amparo à Pesquisa e Inovação do Estado de Santa Catarina (FAPESC). Membra do Laboratório de Pesquisa em Lazer e Atividade Física (LAPLAF/CEFID/UDESC/CNPq).

${ }^{3}$ Mestranda do Programa de Pós-graduação em Ciências do Movimento Humano (PPGCMH) da Universidade do Estado de Santa Catarina (UDESC), com bolsa da Coordenação de Aperfeiçoamento de Pessoal de Nível Superior (CAPES). Membra do Laboratório de Pesquisa em Lazer e Atividade Física (LAPLAF/CEFID/UDESC/CNPq).

${ }^{4}$ Mestranda do Programa de Pós-graduação em Educação Física (PPGEF) da Universidade Federal de Santa Catarina (UFSC), com bolsa da Coordenação de Aperfeiçoamento de Pessoal de Nível Superior (CAPES). Membra do Laboratório de Pesquisa em Lazer e Atividade Física (LAPLAF/CEFID/UDESC/CNPq).

${ }^{5}$ Doutora em Educação Física pela Universidade Estadual de Campinas (UNICAMP). Professora do Programa de Pós-graduação em Educação Física (PPGEF/UFSC) da Universidade Federal de Santa Catarina (UFSC). Professora do Programa de Pós-graduação em Ciências do Movimento Humano (PPGCMH) da Universidade do Estado de Santa Catarina (UDESC). Líder do Laboratório de Pesquisa em Lazer e Atividade Física (LAPLAF/CEFID/UDESC/CNPq).
} 
Este estudo de caso qualitativo reflete sobre a participação feminina na capoeira, a partir da trajetória de uma mulher, mestra de capoeira, em Santa Catarina. Os resultados são apresentados em duas categorias: "Um olhar feminino sobre o ser mulher na capoeira" e "O ofício de mestra de capoeira: ser mestra, ser educadora". Este estudo aponta lutas cotidianas enfrentadas por diversas mulheres, a partir da desconstrução de conceitos e aproximação com espaços e realidades que envolvem a capoeira. A investigada apresenta lições adquiridas em sua trajetória, relacionadas a práticas educativas alternativas e sensíveis, de valorização à capoeira, como elemento da cultura, de resistência e luta contra diferentes barreiras socioculturais.

PALAVRAS-CHAVE: Capoeira. Atividades de Lazer. Mulheres.

\section{A FEMALE LOOK AT WOMEN'S MASTERY AND PARTICIPATION IN CAPOEIRA IN THE GREAT FLORIANÓPOLIS}

ABSTRACT: Capoeira is located in a socio-cultural space, being free to present in its practice social and cultural problems of this environment, such as sexism. This qualitative case study reflects on female participation in capoeira, based on the trajectory of a woman, master of capoeira, in Santa Catarina. The results are presented in two categories: "A female look at being a woman in capoeira" and "The craft of a capoeira master, being a master, being an educator". This study points out the daily struggles faced by several women, from the deconstruction of concepts and approximation with spaces and realities that involve capoeira. The investigated presents lessons learned in her trajectory, related to alternative and sensitive educational practices, valuing capoeira, as an element of culture, resistance, and fight against different socio-cultural barriers.

KEYWORDS: Capoeira. Leisure Activities. Women.

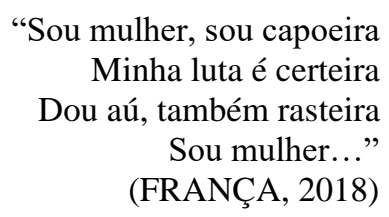

\section{Introdução}

É difícil determinar, do ponto de vista geográfico e temporal, a origem da capoeira. No entanto, é inegável o fato de que se trata de uma manifestação que entrelaça a cultura brasileira com a de diversos povos africanos, e que possivelmente recebeu certa influência indígena (IPHAN, 2014; LUSSAC, 2015). Além disso, considerando que as culturas se constroem em um determinado contexto, ainda que 
existam práticas semelhantes na África, não podemos pensar que a capoeira que conhecemos e experimentamos no Brasil é uma prática restrita às influências africanas (IPHAN, 2014).

Dito isso, ressaltamos que é de extrema importância que reconheçamos as raízes africanas da capoeira, mas sem desconsiderar as mudanças e as transformações que possivelmente ocorreram em solo brasileiro, dando a essa prática, no Brasil, os contornos que a caracterizam como tal. Assim, a capoeira é uma manifestação cultural Afro-brasileira, que nasce no Brasil com os negros que foram escravizados no período colonial (CORRÊA, 2018). Ela se forja no desejo pela liberdade e na luta do povo negro de superar a condição de oprimido, na qual fazem do corpo uma arma de resistências física e cultural (CORRÊA, 2018; PINTO, 2000; PALHARES, 2007). Ou seja, nasce com o regime escravocrata, pela necessidade de um grupo, em um determinado tempo e espaço social.

Como manifestação da cultura, com o dinamismo social, vai se ressignificando nos variados contextos, ocupando diferentes posições e ganhando diversas interpretações ao longo da história (SANTOS, 2009; NORONHA; PINTO, 2004). Hoje, mundialmente conhecida, a capoeira divulga o Brasil pelo mundo, sua língua e cultura, chamando atenção por sua composição singular e complexa, que inclui elementos de jogo, música, dança e luta (IPHAN, 2014). Tal configuração atribui à prática da capoeira características de busca por prazer, desafio, improviso, brincadeira e vadiação (PALHARES, 2007), as quais podem relacionar ao lúdico e ao lazer (LOTT, 2018; SAMPAIO, TAVARES, 2007).

O lúdico é um elemento cujas complexidades e subjetividade torna difícil sua conceituação; portanto, é uma dimensão não conceitual, mas que pode ser apreendida ao se manifestar nos sentidos e significados atribuídos às experiências humanas 
(MARINHO, 2004). Podemos, com a experiência lúdica, ampliar nossos sentidos e formas de interação com o mundo e com as pessoas à nossa volta, abrindo-nos ao imprevisível por valorizar a espontaneidade (SANTIN, 1996; CACHOEIRA; FIAMONCINI, 2019). Nesse sentido, a capoeira se aproxima dessa experiência ao valorizar a expressão livre e espontânea, dando às pessoas a oportunidade de experimentar momentos de liberdade (MARTINS; MARINHO, 2019), permitindo-as ser em verdade e plenitude.

O lazer, por sua vez, pode ser compreendido como um fenômeno social, político, cultural, contra hegemônico, gerado e problematizado historicamente, por ser tratar de uma prática social, influenciada por uma multiplicidade de vivências situadas em distintos contextos socioculturais (GOMES, 2014). Está relacionado com a cultura vivenciada, no seu sentido mais amplo, de forma livre e desinteressada, ativa ou contemplativa, que envolve aspectos de tempo e atitude, bem como, proporciona questionamentos da sociedade exercendo influência nas estruturas sociais (MARCELLINO, 2007).

Para Gomes (2014, p. 12), o lazer possui significados e sentidos particulares para aqueles que o vivenciam, e em virtude da "necessidade de fruir, ludicamente, as incontáveis práticas sociais constituídas culturalmente", podemos o considerar como necessidade humana e dimensão da cultura. Nesse sentido, as manifestações de lazer podem contribuir para mudanças de ordens moral e social, gerando possibilidades lúdicas, educativas e de desenvolvimento pessoal e social (MARCELLINO, 2007).

Em sua pesquisa sobre a capoeira de rua, Melo (2015) aponta que a capoeira socialmente comprometida, enquanto possibilidade de lazer, apresenta contradições e tensões que a diferenciam de perspectivas de lazer que o veem como algo desinteressado e que se contrapõe ao trabalho. Portanto, devemos considerar que lazer, 
trabalho, relações sociais e movimentos sociais se relacionam com os processos de constituição das subjetividades humanas, possuindo dinâmicas complexas de desenvolvimento, que nos permitem conceber a capoeira como um lazer de caráter transgressor e de contraposição a alguns mecanismos sociais de desigualdade e opressão (MELO, 2015).

Ainda que esteja fundamental e historicamente relacionada a movimentos de contraposição à opressão e na busca por libertação, a capoeira está situada em um espaço sociocultural e, portanto, não está livre de apresentar em sua prática (contraditoriamente) as mazelas sociais desse mesmo espaço, dentre elas, o machismo. Historicamente, a rua é considerada um espaço eminentemente masculino, sendo, assim, tecidas relações de supremacia de gênero, ressaltando as liberdades do "poder do macho", conforme descrito por Oliveira e Leal (2009, p. 119).

Sob uma perspectiva machista, nas primeiras décadas do século $\mathrm{XX}$, a participação das mulheres em espaços sociais deveria ser sutil, discreta e diferenciada de acordo com sua classe social, popular ou elitizada (OLIVEIRA; LEAL, 2009). Ferreira Filho (1994, p. 99) elucida que "na conquista do espaço público, as mulheres pobres tiveram um papel fundamental. Ágeis, versáteis, econômicas, políticas, essas mulheres foram, no contexto da cidade, os exemplares mais significativos dos que venceram o desafio da rua". À medida que se inseriram nos contextos socioculturais, elas, assim como os homens que participavam das rodas de capoeira, foram perseguidas por um discurso civilizador, no qual eram identificadas como "mulheres valentes", responsáveis pela desordem nas ruas (OLIVEIRA; LEAL, 2009).

No entanto, devemos alertar para o fato que, mesmo presentes nas rodas, as mulheres seguem sofrendo com as desigualdades de gênero, pois a capoeira continua sendo praticada majoritariamente por homens (SOUZA, 2010; BARBOSA, 2017; 
FRANÇA, 2018). Nessa perspectiva, Barbosa (2017) observa que, para a mulher permanecer na capoeira, é preciso coragem e persistência, pois muitos são os desafios e as violências, visto que esta é uma prática historicamente considerada masculina, resultando em maior contingente masculina de participantes e nas posições de liderança (mestres, contramestres e professores).

Além disso, existe uma invisibilidade do papel da mulher na capoeira, pois poucos são os estudos que procuram explorar as questões que estão envolvidas no ser mulher capoeirista (BARBOSA, 2017). Portanto, torna-se substancial que possamos estudar a capoeira, também, a partir da perspectiva feminina, dando às mulheres voz e espaço para que possam compartilhar suas experiências, a partir das quais podemos tentar nos aproximar desse contexto para compreendê-lo e transformá-lo. Nesse sentido, este estudo tem como objetivo refletir sobre a participação feminina na capoeira, a partir da trajetória de uma mulher, mestra de capoeira, em Santa Catarina.

\section{Metodologia}

Do ponto de vista metodológico, esta pesquisa caracteriza-se como um estudo de caso que incluiu uma pesquisa exploratória e descritiva, bem como possui uma abordagem qualitativa. Os estudos de caso têm como propósito estudar determinado objeto, com o intuito de realizar um amplo detalhamento e aprofundamento do contexto investigado (YIN, 2014; PEREIRA; GODOY; TERÇARIOL, 2009; FREITAS; JABBOUR, 2011).

Além disso, Yin (2014) defende que o referido caso estudado deve ser representativo para justificar uma busca aprofundada sobre determinada situação e/ou contexto. Nesse sentido, a importância deste estudo se dá pelo caso investigado ser a trajetória de uma mulher que possui evidente importância para capoeira da Grande 
Florianópolis ${ }^{6}$ no estado de Santa Catarina. A mulher investigada é, até então, a única no estado de Santa Catarina a ter recebido o título de mestra de capoeira (que iniciou a sua trajetória no estado e recebeu o título no mesmo), estando inserida em um contexto, no qual a capoeira existe, de forma estruturada, há mais de 40 anos, rodeada por um universo de mestres homens. Esta mulher será identificada neste estudo pelo nome fictício de Mestra Violeta.

Este estudo faz parte de um projeto de pesquisa enviado ao Comitê de Ética e Pesquisas com Seres Humanos da Universidade do Estado de Santa Catarina, o qual foi aprovado sob o parecer $n^{\circ} 3.083 .715$, seguindo os preceitos éticos da Resolução 510/16 do Conselho Nacional de Saúde sobre pesquisa com seres humanos. Ressalta-se que a Mestra Violeta aceitou participar voluntariamente deste estudo e assinou um Termo de Consentimento Livre e Esclarecido.

As pesquisas exploratórias objetivam maior familiarização com o problema, considerando os diferentes aspectos inerentes ao fenômeno estudado (GIL, 2010). Por sua vez, as pesquisas descritivas, de acordo com Gil (2010), têm o propósito de descrever detalhadamente as características dos elementos investigados e, se possível, verificar as relações entre os achados, podendo ter o intuito de levantar opiniões, atitudes ou crenças de determinado grupo.

Segundo Freitas e Jabbour (2011), para a realização de pesquisas que adotam como estratégia o estudo de caso é preciso, primeiro, definir qual abordagem responderá melhor os objetivos da pesquisa (quantitativa ou qualitativa). Assim, para esses mesmos autores, quando "a finalidade é explicar ou descrever um evento ou uma situação, a

\footnotetext{
${ }^{6} \mathrm{O}$ termo Grande Florianópolis refere-se a região Metropolitana de Florianópolis, que inclui os municípios de Águas Mornas, Antônio Carlos, Biguaçu, Florianópolis, Governador Celso Ramos, Palhoça, Santo Amaro da Imperatriz, São José, São Pedro de Alcântara, Alfredo Wagner, Angelina, Anitápolis, Canelinha, Garopaba, Leoberto Leal, Major Gercino, Nova Trento, Paulo Lopes, Rancho Queimado, São Bonifácio, São João Batista e Tijucas (SANTA CATARINA, 2010).
} 
abordagem adotada deve ser a qualitativa" (p. 9). Além disso, a pesquisa qualitativa não pode ser quantificada e está estreitamente relacionada com o universo dos significados, motivos, atitudes e valores (MINAYO, 2012).

O principal benefício desse tipo de abordagem diz respeito à possibilidade de triangular os dados por meio de diversos instrumentos: entrevistas, observações, análise de documentos; uma vez que essa triangulação aproxima o pesquisador do objeto de estudo (FREITAS; JABBOUR, 2011), bem como contribui para uma melhor compreensão do fenômeno investigado.

Para tanto, foi realizada uma entrevista semiestruturada com a Mestra Violeta. Este tipo de instrumento, conforme Minayo (2012), é um dos mais utilizados nas ciências sociais, tendo o objetivo coletar informações, de um ou mais conteúdos específicos, por meio da comunicação verbal. Para esse estudo, optou-se pela entrevista semiestruturada, com perguntas abertas, na qual a entrevistada foi incentivada a discorrer sobre suas experiências, motivações, crenças, e inquietações relacionadas ao universo da capoeira.

Foi utilizado um roteiro pré-estruturado, delineado, especificamente, para esse estudo, a fim de orientar a entrevistadora, porém, não nos limitamos a ele. Essa estrutura de entrevista possibilita que o (a) entrevistador (a) explore as questões de interesse do estudo, bem como, possui a flexibilidade de aprofundar nas respostas dadas pelos (as) entrevistados (as), resultando, assim, em um amplo arsenal de dados (PATTON, 2002).

A entrevista ocorreu em uma escola pública da Grande Florianópolis, onde a Mestra Violeta desenvolve um projeto de capoeira no contraturno escolar, sendo marcada previamente, em comum acordo com a entrevistada; teve duração de 42 minutos, e foi gravada, em sua totalidade, com auxílio de um gravador de áudio e, posteriormente, transcrita na íntegra (aproximadamente, quatro horas de transcrição). 
Destaca-se que, conforme aconselhado por Halcomb e Davidson (2006), para diminuir o viés de transcrição, a pesquisadora principal foi quem realizou a entrevista e a transcreveu. Além disso, a entrevistadora possui experiência, tanto com o instrumento de coleta de dados, quanto com a capoeira, além de ter acompanhado, por quatro meses, por meio de observação participante, a Mestra Violeta em seu projeto de capoeira, na escola em que ela leciona.

Salientamos que, para registro de informações, a pesquisadora contou com o auxílio de um diário de campo. Autores como Minayo (2013) e Oliveira (2014) observam que este elemento pode ser caracterizado como substancial para o desenvolvimento da pesquisa, pois carrega anotações do trajeto, que recuperam a memória de aspectos observados, vivenciados e sentidos durante o período de coleta de dados.

Os dados coletados foram analisados por meio de elementos da técnica de análise de conteúdo, seguindo as orientações de Bardin (2009). Para a autora, a análise de conteúdo se caracteriza como um conjunto de técnicas de análise de comunicações, realizada por meio de procedimentos sistemáticos, os quais se dividem em três categorias, a saber: a pré-análise, que corresponde a fase inicial de organização dos dados, realizando a leitura do material, a elaboração dos indicadores que auxiliam na interpretação dos dados, e a seleção dos documentos que serão analisados. Posteriormente, a primeira fase, parte-se para a exploração do material, que consiste em realizar as codificações e unidades de registros, e por fim, é realizado o tratamento dos dados, a partir da inferência e a interpretação, sendo respaldado no referencial teórico (BARDIN, 2009). A partir disso, os principais resultados encontrados foram discutidos nas categorias: "Um olhar feminino sobre o ser mulher na capoeira" e "O ofício de mestra de capoeira: ser mestra, ser educadora". 


\section{Resultados e Discussão}

Por meio dos relatos da Mestra Violeta, obtidos em sua entrevista, além da observação cuidadosa do seu trabalho de capoeira, pudemos conhecer e nos aproximar dessa mulher, mestra de capoeira, forte, determinada e que demonstrou, durante todo o período do estudo, muita dedicação e paixão pela capoeira. No que pode ser alcançado por esta pesquisa, sobre seu trabalho e trajetória na capoeira, destacam-se duas questões: o olhar feminino sobre o ser mulher na capoeira, na Grande Florianópolis, discutido a partir da experiência dessa mestra; e os aspectos relacionados ao ofício de mestra de capoeira (ser mestra, ser educadora e seus desdobramentos).

\section{Um Olhar Feminino sobre o Ser Mulher na Capoeira}

A Mestra Violeta iniciou a sua trajetória na capoeira em 1983, na Grande Florianópolis, com 15 anos de idade e com poucas referências femininas na capoeira. Também para Corrêa (2018), pesquisadora na área da Educação, conhecida na capoeira como Contramestra Jô, quando iniciou a capoeira em 1988 (na mesma região que a Mestra Violeta), existiam poucas mulheres que praticavam essa modalidade, a qual era socialmente considerada como algo destinado ao público masculino. A ausência de outras mulheres na capoeira, representativas e referências para as que vão iniciando a prática, é uma questão que surge na fala da Mestra Violeta, evidenciando a dificuldade de uma geração a qual ela faz parte, das primeiras mulheres na história da capoeira da Grande Florianópolis, a levarem essa prática para a vida.

\footnotetext{
Também tive os meus momentos de desânimo em algumas cordas assim... Eu balancei entre ficar e voltar, por causa dos perrengues que a gente enfrenta na capoeira, as dificuldades, os treinos, a cobrança, opressão de tu ter que fazer as coisas que tu não queres e, também, de ter que treinar só com homem e é difícil treinar só com homem (Mestra Violeta).
} 
Mesmo com as dificuldades, algumas (poucas) mulheres daquela época permaneceram na capoeira da Grande Florianópolis, a exemplo da Contramestra Jô e da Mestra Violeta, quem chegou ao título de mestra de capoeira em 2016 (IPHAN, 2017), após 33 anos dedicados à esta prática.

Embora, na adolescência, tenha iniciado a capoeira por sua afinidade com esportes e lutas, sem um olhar crítico para sua posição enquanto mulher dentro da capoeira, com o passar do tempo e com as experiências vividas, Mestra Violeta percebeu a sua missão como mulher neste contexto, devido ao machismo estrutural. $\mathrm{O}$ que podemos identificar em sua fala:

[...] eu comecei a ter maior entendimento da minha prática e da militância, da minha missão enquanto mulher na capoeira, mestra, feminista, de estar sempre lutando em prol da equidade, principalmente em prol das mulheres, porque a gente sabe que as nossas dificuldades são muito maiores para se manter na capoeira e para chegar à mestra do que a dos homens (Mestra Violeta).

Percebemos o alerta que a Mestra Violeta faz sobre as dificuldades enfrentadas pela mulher na capoeira e como, para ela, a compreensão dessa situação não foi imediata. Sobre isso, as estruturas machistas são tão predominantes na nossa sociedade que, muitas vezes, as mulheres naturalizam certas violências sofridas (BARBOSA, 2017). Nesse sentido, a mulher quando identificada como "sexo frágil" tende a sofrer uma estigmatização do corpo como inapropriado para tal prática, que possui um caráter combativo, o qual pode assumir um formato duro ou violento. Tais relações são complexas. Sobre isso, a Mestra Violeta afirma:

[...] mas como a gente é jovem e está naquele auge de evolução física e pelo fato de ter muita competitividade, eu me atraio também por isso, então não tinha entendimento, não parava pra pensar sobre isso que a gente treinava pra ir pra roda pra trocar porrada com outras pessoas, não tinha esse entendimento né, a gente só vai entender isso quando amadurece, isso leva tempo. Bem depois que eu fui entender e ter uma outra visão disso, de que a gente não está na capoeira só para isso, pra trocar porrada, ela (a capoeira) tem muitas coisas maravilhosas para a gente se manter nela e não só esse lado da luta entre a gente sabe, porque ninguém aguenta lutando uma vida inteira, 
uma hora o corpo cansa, o corpo se machuca, as lesões começam a aparecer (Mestra Violeta).

Ao considerar o contexto sociocultural em que a Mestra Violeta se encontrava, no início de sua prática, observamos que as atividades culturalmente associadas ao feminino, distanciam-se do contato físico e da combatividade presentes na capoeira. Importante destacar que, até 1979, alguns anos antes, a prática de algumas atividades físicas, como judô, futebol e capoeira, eram proibidas por lei de serem realizadas por mulheres. Acreditava-se que a fragilidade feminina e a maternidade deveriam ser preservadas (SOUZA, 2010).

Neste mesmo segmento, na sociedade patriarcal em que nós vivemos, características como valentia, agilidade, habilidade e força estão, normalmente, associadas ao universo masculino, e não ao feminino; uma vez que a mulher era considerada como sensível, amável e dependente do homem (DA VITÓRIA, 2015). Além disso, apesar de a capoeira (numa perspectiva ampla) não ter gênero e ser uma resposta às opressões sofridas pelo povo negro, as condições impostas às mulheres (submissão, responsabilidades e tarefas da casa), pela sociedade da época, contribuíram para a falta das mulheres no meio capoeirístico (DA VITÓRIA, 2015).

Assim, a inserção de mulheres na capoeira, mesmo após a extinção da lei, foi encoberta de barreiras socioculturais, nas quais os próprios profissionais da saúde, como médicos e fisiologistas, e os educadores, desaconselhavam a prática (MOURÃO; SOUZA, 2007). Como reflexo, também, dessa sociedade machista, quando as mulheres transgrediram as condições socioculturais supracitadas, e passaram a utilizar a capoeira no seu cotidiano, elas recebiam adjetivos como "valentonas" e "briguentas", enquanto os homens eram vistos como destemidos e ágeis (DA VITÓRIA, 2015). Esses aspectos desembocaram em preconceitos e dificuldades relacionados à participação das mulheres 
na capoeira, os quais ainda existem, embora muito se faça para superá-los. Sobre isso, a

Mestra Violeta argumenta:

Sempre pra mulher é mais difícil tudo, porque a mulher tem outras funções além de só treinar a capoeira né, ela tem normalmente filhos e casa ou se casa com alguém e aí ela tem aquela obrigação que a sociedade impõe, né: que ela tem que casar e ter filhos. Então, para treinar capoeira, uma arte que precisa de bastante dedicação, é mais difícil. E a gente vê que na capoeira o número de mulheres é sempre mais baixo do que o de homens. Normalmente, quando existe uma relação de um casal e eles terminam, a mulher sai e o homem fica. A gente está tentando fazer essa mudança, mas não é fácil (Mestra Violeta).

Conforme Da Vitória (2015), da mesma forma como nos demais espaços, as construções sociais perpassam pelas relações sociais. Assim, a autora afirma que a capoeira, também, constitui-se com a presença do patriarcado, onde, por vezes, a imagem da mulher é manchada, a exemplo, inclusive, de algumas cantigas de roda. Barbosa (2017), ao pesquisar a trajetória de seis mulheres na capoeira em Porto Alegre, destaca que diferentes mulheres reagem de diferentes formas às várias violências que podem se apresentar, desde a constante invisibilização na prática da capoeira, até opressão, assédio moral e/ou sexual.

Em concordância, Da Vitória (2015) afirma que falas e atitudes machistas ocorrem de forma rotineira no contexto da capoeira e isso fez com que um grupo de mulheres capoeiristas se reunissem para discutir as violências, as experiências e as vivências que haviam passado, o que as fez perceber a importância de terem o apoio umas das outras. Buscando vencer os preconceitos, algumas mulheres encontraram como alternativa assumir uma postura que nem sempre condizia com quem elas eram em verdade, buscando um perfil "masculinizado", dentro de uma atribuição social do que seria masculino, para ser respeitada em meio aos outros participantes e mestres. Assim como ressaltado no discurso de Mestra Violeta: 
[...] nós somos mulheres, então é um contexto totalmente diferente, às vezes a gente tem que se transformar numa coisa que a gente não é para poder se manter ali. E hoje eu consigo perceber isso, que muitas vezes eu tive que agir igual homem, com atitudes de homem, se não, eu não conseguiria ter sobrevivido aquela época, sabe? Porque a gente trocava porrada na roda e vinha pra casa toda machucada e tinha que aguentar aquilo, tu tinhas que ser forte (Mestra Violeta).

O relato da Mestra Violeta diz respeito às dificuldades pessoais, mas que podem ser interpretadas como uma forma de resistência do próprio movimento feminista, dentro da capoeira. Para além dos preconceitos referentes a aspectos físicos, características como coragem e racionalidade, são comumente atribuídas aos homens (FRANÇA, 2018). Portanto, ainda que as mulheres tenham conquistado seu espaço, discursos e ações machistas seguem persistindo em diferentes espaços sociais.

Contudo, estudos como o de França (2018) mostram a importância de desconstruir conceitos e repensar discursos que contribuam para o aumento da desigualdade de gênero, por meio da visibilidade da mulher e do conhecimento sobre a história da capoeira. Além disso, de acordo com a autora, é necessário que a prática seja vivenciada de forma inclusiva, em que a mulher não seja vista como um corpo frágil. Nessa perspectiva, Mestra Violeta esperançosamente destaca:

[...] agora que está tendo um outro formato, as pessoas estão procurando estudar, se adequar, procurar conhecer o corpo em todos os sentidos, mas é muito recente. A gente tenta ir melhorando com o trabalho que a gente faz, com as crianças, mas é difícil, as dificuldades estão aí, o machismo, o preconceito é muito forte (Mestra Violeta).

Assim, percebe-se o quão desafiador pode ser para a mulher - por ser mulher seguir seu caminho na capoeira. Contudo, aquelas que o fazem, tornam-se, possivelmente, a exemplo da Mestra Violeta, educadoras da capoeira que, à luz das dificuldades pelas quais passaram, buscam moldar suas práticas pedagógicas para valorizar a mulher nesse espaço, contribuindo para uma sociedade mais justa e igualitária. 


\title{
O Ofício de Mestra de Capoeira: Ser Mestra, Ser Educadora
}

Evidenciou-se na fala da Mestra Violeta, e nas ações perante seus alunos, uma compreensão de que a busca por conhecimento e processos educativos são uma possibilidade de superação das condições de preconceito e opressão que socialmente se estabelecem.

\begin{abstract}
Não pretendo formar atletas (...) eu passo valores para eles, valores que eu aprendi com a minha família, com as minhas vivências, os valores que a gente precisa respeitar as diferenças, ter educação, saber entrar e saber sair, não mexer nas coisas de ninguém. Enfim, valores que a gente vai aprendendo com a vida, para lá na frente nos tornarmos boas pessoas, porque eu acredito que a gente ainda pode contribuir para fazer um mundo melhor, mais igual (Mestra Violeta).
\end{abstract}

Para Palhares (2007), a capoeira é capaz de favorecer processos educativos para a aquisição de valores socioculturais, contribuindo para a inclusão social e as relações igualitárias. Nesse sentido, o lúdico na capoeira se apresenta como uma alternativa fértil, podendo ser explorado para a construção de ambientes pedagógicos que contribuam para processos significativos de ensino e aprendizagem, tendo a figura do (a) professor (a) um papel fundamental nesse cenário (MARTINS; MARINHO, 2019).

Em sua trajetória profissional, Mestra Violeta buscou outras fontes de conhecimento, tornando-se pedagoga e licenciada em Educação Física. Ao entrar no sistema formal de educação, como professora, vieram o gosto e a vontade, também, de trabalhar com a capoeira, utilizando conhecimentos específicos dessa prática que foram adquiridos anteriormente à formação universitária.

\begin{abstract}
Então, eu dava aula de Educação Física e eu a colocava (a capoeira) nas minhas aulas, como uma outra atividade e aí eu fui pegando o gosto por ela, por também praticar, fazer muito mais do que as aulas de Educação Física. Daí eu comecei a dar aula de capoeira em 98 aqui no colégio, não tinha nada a ver com a prefeitura, eu vim aqui oferecer e eles aceitaram por ser uma modalidade diferente (Mestra Violeta).
\end{abstract}

O ser professor, a construção da identidade docente, ocorre em processos que vão se estabelecendo ao longo de toda a vida, iniciando antes da formação inicial e 
continuando posteriormente a ela, sendo este percurso influenciado pelas escolhas e experiências individuais de cada pessoa (RESENDE et al., 2014). Assim, não devemos generalizar como se torna professor, considerando a subjetividade que cada um expressa em suas trajetórias individuais (BOLZAN; ISAIA, 2010).Tal compreensão pode ser pensada, também, na construção da identidade de mestra de capoeira que, após a experiência com esta prática em sala de aula, teve certeza de que queria trabalhar com isso. Então, iniciou suas atividades como professora de capoeira e passou a investir mais na sua formação para essa ação específica.

\begin{abstract}
Eu já tinha bastante facilidade para dar aula, eu já gostava de fazer isso, então eu não tive problema com forma de trabalhar, didática, só se encaixou assim, só mudou a modalidade e daí eu comecei a trabalhar com pessoas que queriam fazer capoeira, não era mais aula de Educação Física (...) era opcional, então ficou uma coisa melhor vamos dizer. Eu pude desenvolver mais habilidade, a forma de trabalhar, a fundamentação da capoeira, pude estudar muito mais isso, me aprofundar em todos os fundamentos relacionados a capoeira: de jogo, fundamentos de golpe, fundamentos de ritmo, de canto, história. Aprimorei mais os meus conhecimentos com a capoeira, tanto físico quanto intelectual, histórico, ancestral (...) então, foi bem bom isso, cada vez fez mais com que eu me envolvesse mais, quisesse mais ficar na capoeira (Mestra Violeta).
\end{abstract}

A ancestralidade, enquanto manifestação simbólica da cultura de outrora, revelase, também, nas crianças, quando estas se expressam livremente na corporeidade, no jogo e na musicalidade da capoeira (MARTINS; MARINHO, 2019). Os aspectos histórico e ancestral são características próprias e fundamentais dos saberes da capoeira, dos quais os mestres (as) são guardiões e promotores, o que lhes confere grande respeito por parte dos capoeiristas (CORDEIRO; ABIB, 2018; JESUS; GRUBER, 2017). Assim, embora reconheça a importância de se buscar conhecimento em instituições formais de educação, que possam complementar a sua atuação com a capoeira, Mestra Violeta destaca o quão fundamental é reconhecer e valorizar os conhecimentos histórico e popular que cercam o universo da capoeira. 
Não é um semestre no curso de Educação Física e o cara está apto para dar aula de capoeira, não está mesmo. Nem com quatro anos a gente não sai sabendo muitas coisas. Ele tem que ter alguns anos dentro da prática da capoeira para poder dar aula (...) eles (instituições) querem pedir a formação acadêmica e a gente sabe aí que os grandes mestres não têm essa formação acadêmica. Eles têm a formação da vida, da história, eles não sentam num banco de universidade, mas o conhecimento deles é muito maior do que um banco de universidade, eles têm o saber popular, o saber da rua, da ancestralidade (Mestra Violeta).

Nesse contexto, a figura do (a) mestre (a) é certamente uma referência importante na formação dos alunos que passam pela capoeira, pois, muito vinculado ao ensino da capoeira estão os aspectos educacionais em uma perspectiva mais ampla, pensando em valores e atitudes importantes na construção de uma sociedade mais justa e igualitária. Para tanto, deve-se valorizar a capoeira de maneira educacional como cultura e possibilidade lúdica (KOHL, 2014). Cabendo a figura de o educador ter um olhar sensível sobre esses aspectos, tal qual a Mestra Violeta apresenta:

[...] poder passar o teu conhecimento, aquilo que tu aprendeste, tu ver as crianças se divertindo quando aprendem a capoeira, curtindo a parte da instrumentalização da capoeira, a música, se defendendo, sabendo se respeitar numa roda, sabendo se respeitar na hierarquia do jogo, tocando, cantando, evoluindo né, levando todo esse aprendizado para vida, porque acontece que a gente às vezes dá aula para um aluno ali de 7 anos e 20 anos depois ele vem trazer o filho para treinar capoeira. Ele não consegue se manter na capoeira, mas traz o filho ou a filha [...] é prazeroso ver aquelas pessoas que tu um dia foi referência e passou algum conhecimento, elas seguindo um caminho do bem e se tornando boas pessoas, acho que isso é o mais gratificante (Mestra Violeta).

Como um fenômeno sociocultural, a capoeira se manifesta na sociedade de distintas formas (SAMPAIO; TAVARES, 2007). Independentemente de onde aconteça, seja na favela (KANITZ, 2011), ou em grandes centros urbanos (LOTT, 2018), a capoeira corrobora a inclusão social, por meio do movimento, da arte e da música (PALHARES, 2007). Por isso, é de suma importância que a capoeira esteja presente nos ambientes formais de ensino, sendo explorada crítica e contextualizadamente (PALHARES, 2007). Após trabalhar 21 anos com a capoeira na escola, Mestra Violeta, compreende como um conteúdo fundamental 
[...] quando uma criança chega aqui, por exemplo, ela é uma criança que a escola pede para ela ser inserida na prática da capoeira, porque ela é uma criança agressiva. E o trabalho metodológico, didático e afetivo, que a gente faz dentro da capoeira, consegue direcionar aquela criança para que ela tenha um outro foco com a agressividade dela, porque às vezes ela tem um problema de desestrutura próprio da família, sabe? E daí ela traz aquela carga que ela não consegue trabalhar, porque ela é uma criança. Aqui a gente consegue ter essa percepção, direcionar o que está acontecendo com ela, como a gente vai agir com aquela criança para direcionar aquela agressividade (Mestra Violeta).

Nesse sentido, ao transbordar os aspectos técnicos da capoeira em suas aulas, a Mestra Violeta tem um olhar sensível para com seus alunos. Trata-se de uma ação pedagógica orientada pelo saber da experiência, o qual é saber subjetivo e pessoal (BONDÍA, 2002). Por usa vez, a reflexão é o processo que transforma uma experiência em um aprendizado que virá a compor esse saber (RESENDE et al., 2017). Assim, à luz do exposto pela Mestra Violeta, cabe ressaltar o quão importante é a figura dessa mestra e sua trajetória para a efetivação da capoeira como processo educativo de transformação sociocultural nas suas aulas.

\section{Considerações Finais}

Este estudo de caso realizado com a Mestra Violeta levantou importantes discussões que, acima de tudo, estão em sintonia com os estudos de Barbosa (2017). Esta autora afirma que investigar e refletir sobre a trajetória da mulher na capoeira, a partir da própria mulher, significa valorizar pontos de vista diferentes e inovadores, permitindo-nos compreender melhor como essas mulheres realizam suas experiências. Essencialmente, a experiência é o que nos passa, acontece e toca, e não, o que se passa, acontece ou toca (BONDÍA, 2002).

Nessa perspectiva, a experiência sendo "o que nos acontece" e não "o que acontece", duas pessoas que passam pelo mesmo acontecimento não têm a mesma experiência e, portanto, o saber da experiência não se separa do indivíduo em que surge 
(BONDÍA, 2002). Assim, devemos mencionar o caráter não generalizável deste estudo, ressaltando, porém, que se pode levantar e elucidar, a partir dele, questões pertinentes a serem discutidas sobre a participação das mulheres na capoeira.

Das experiências mencionadas pela Mestra Violeta e da vivência que se estabeleceu durante os quatro meses de observação do trabalho dessa mestra, foram evidenciadas as dificuldades enfrentadas por ela para permanência na capoeira, e como essa trajetória de vida a influenciou como educadora que valoriza as práticas educativas alternativas e sensíveis, buscando ressignificar aspectos socioculturais.

Dessa forma, Leiro (2002) relembra que as relações de gênero presentes no lazer também sofrem influências culturais, as quais podem influenciar a vida como um todo. Apesar de algumas mulheres, como a Mestra Violeta e a Contramestra Jô, tentarem romper tensões e fronteiras entre gêneros, observadas no meio capoeirístico, elas ainda não foram completamente rompidas.

A capoeira, como forma de manifestação da cultura, carrega o significado de resistência e representa a luta contra diferentes barreiras sociais. Contudo, há ainda um caminho de reconhecimento da mulher, nesse espaço, a ser conquistado. Para que sejam valorizadas como igualmente pertencentes a essa manifestação. Para isso, torna-se importante, como aponta Da Vitória (2015), que as mulheres praticantes passem a apoiar umas às outras. Atitude esta que a Mestra Violeta já apresenta em sua busca em prol das mulheres e da equidade de gênero na capoeira, contribuindo para uma sociedade mais justa e igualitária.

Nessa perspectiva, compartilhamos da defesa de França (2018) sobre a importância de estudos que dêem visibilidade e estimulem o protagonismo de mulheres, inclusive na pesquisa. Assim, pode ser possível retratar as lutas cotidianas enfrentadas por diversas mulheres, por meio de um olhar feminino. Buscando um avanço nas 
discussões a partir da desconstrução de conceitos e aproximação com os espaços e as realidades. Com isso, sugerimos que novos estudos sejam realizados com outras mulheres, mestras, ou não, em diferentes contextos, com o propósito de nos aproximarmos de compreensões mais amplas sobre a participação delas na capoeira.

\section{REFERÊNCIAS}

BARBOSA, V. M. Mulher na roda: experiências femininas na capoeira angola de Porto Alegre. 2017. 159 f. Dissertação (Mestrado em Educação) - Faculdade de Educação, Universidade Federal do Rio Grande do Sul, Porto Alegre, 2017.

BARDIN, L. Análise de conteúdo. Lisboa: Edições 70, 2009. 229 p.

BOLZAN, D. P.; ISAIA, S. M. A. Pedagogia universitária e aprendizagem docente: relações e novos sentidos da professoralidade. Revista Diálogo Educacional, Curitiba, v. 10, n. 29, p. 13-26, 2010.

BONDÍA, J. L. Notas sobre a experiência e o saber da experiência. Revista Brasileira de Educação, Rio de Janeiro, n. 19, p. 20-31, 2002.

CACHOEIRA, N. R.; FIAMONCINI, L. A ludicidade no projeto de extensão vivências corporais lúdicas na UFSC. Licere, Belo Horizonte, v. 22, n. 3, p. 401-424, 2019. DOI: https://doi.org/10.35699/1981-3171.2019.15317

CORDEIRO, A. A. S.; ABIB, P. R. J. A educação da capoeira: uma pedagogia da cultura popular. Educação em Foco, Minas Gerais, v. 21, n. 33, p. 223-241, 2018.

CORRÊA, J. P. A arte de ensinar a capoeira, na roda e na vida: pedagogia da capoeiragem de Norival Moreira de Oliveira - Mestre Nô. 2018. 111 f. Dissertação (Mestrado em Educação) - Centro de Ciências da Educação, Universidade Federal de Santa Catarina, Florianópolis, 2018.

DA VITÓRIA, A. A malta de saias ginga na UFRN: desconstruindo o machismo na roda viva. Revista Interface-UFRN/CCSA, Rio Grande do Norte, v. 12, n. 2, p.106$119,2015$.

FERREIRA FILHO, A. H. Salvador das mulheres: condição feminina e cotidiano popular na Belle Époque Imperfeita. 1994. 223 f. Dissertação (Mestrado em História) Faculdade de Filosofia e Ciência Humanas da UFBA, Salvador, 1994.

FRANÇA, A. L. O protagonismo da mulher nas produções científicas sobre capoeira como temática. Revista Íbamò, Rio de Janeiro, v. 1, n. 1, p. 90-103, 2018.

FREITAS, W. R. S.; JABBOUR, C. J. C. Utilizando estudo de caso (s) como estratégia de pesquisa qualitativa: boas práticas e sugestões. Revista Estudo \& Debate, Lajeado, v. 18, n. 2, p. 7-22, 2011. 
GIL, A. C. Como elaborar projetos de pesquisa. 5. ed. São Paulo: Atlas, 2010. 200 p.

GOMES, C. L. Lazer: necessidade humana e dimensão da cultura. Revista Brasileira de Estudos do Lazer, Belo Horizonte, v. 1, n. 1, p. 3-20, 2014.

HALCOMB, E. J.; DAVIDSON, P. M. Is verbatim transcription of interview data always necessary? Applied nursing research, Filadélfia, v. 19, n. 1, p. 38-42, 2006.

IPHAN (Instituto do Patrimônio Histórico e Artístico Nacional). Roda de Capoeira e ofício dos mestres de capoeira/ Instituto do Patrimônio Histórico e Artístico Nacional - Brasília: Distrito Federal. 2014.

- Cadastro Nacional da Capoeira. 2017. Disponível em: https://www.capoeira.gov.br/. Acesso em: 20 nov. 2020.

JESUS, F. S.; GRUBER, V. A estética da (re) existência: olhares filosóficos sobre o mestre de capoeira. In: XIII Encontro de Estudos Multidisciplinares em Cultura, 2017, Salvador. Anais [...] Salvador, BA: UFBA, 2017.

KOHL, H. G. Gingado na prática pedagógica escolar: expressões lúdicas no que fazer da educação física. 2. ed. Recife: Editora UFPE, 2014. 137 p.

KANITZ, R. C. M. Capoeira angola na favela: juventudes, sentidos e redes sociais. Belo Horizonte, 2011. 152 f. Dissertação (Mestrado em Lazer) - Escola de Educação Física, Fisioterapia e Terapia Ocupacional, Universidade Federal de Minas Gerais, Belo Horizonte, 2011.

LEIRO, A. C. R. Educação, Lazer e Relações de Gênero: talhes e doxas. Motrivivência, Florianópolis, v. 19, p. 1-16, 2002.

LOTT, W. P. A Capoeira no Brasil: da proibição à salvaguarda. Licere, v. 21, n. 4, p. 450-470, 2018. DOI: http://doi.org/10.35699/1981-3171.2018.1949.

LUSSAC, R. M. P. Especulações acerca das possíveis origens indígenas da capoeira e sobre as contribuições desta matriz cultural no desenvolvimento do jogo-luta. Revista Brasileira de Educação Física e Esporte, São Paulo, v. 29, n. 2, p. 267-278, 2015.

MARCELLINO, N. C. Lazer e Cultura: algumas aproximações. In: MARCELLINO, N. C. (org.). Lazer e Cultura. Campinas: Editora Alínea, 2007. p. 9-30.

MARINHO, A. Repensando o lúdico na vida cotidiana: atividades na natureza. In: SCHWARTZ, G. M.(org.). Dinâmica lúdica: novos olhares. São Paulo: Manole, 2004. p. 1-16.

MARTINS, S. E.; MARINHO, Alcyane. A capoeira e o lúdico na escola: reflexões sobre os processos de ensino-aprendizagem. 2019. 16 f. Trabalho de Conclusão de Curso (Graduação em Licenciatura em Educação Física) - Centro de Ciências da Saúde e do Esporte, Universidade do Estado de Santa Catarina, Florianópolis, 2019.

MELO, V. T. Os capoeiras de rua de Belo Horizonte (1970 - 1990): permanências e descontinuidades na história da capoeira. Licere, Belo Horizonte, v. 18, n. 2, p. 221242, 2015. DOI: http://doi.org/10.35699/1981-3171.2015.1108. 
MINAYO, M. C. S. O desafio da pesquisa social. In: MINAYO, M. C. S.; DELANDES, S. F.; GOMES, R. (org.). Pesquisa social: teoria, método e criatividade. 32. ed. Petrópolis: Vozes, 2012. p. 9-29.

Hucitec, 2013. 282 p.

MOURÃO, L.; SOUZA, G. C. Narrativas sobre o Sul-Americano de Judô de 1979: a legalização do judô feminino no Brasil. In: GOELLNER, S. V; JAEGER, A. A.(org.). Garimpando Memórias: Esporte, Educação Física, Lazer e Dança. Porto Alegre: UFRGS, 2007. p. 97-114.

NORONHA, F. D. A.; PINTO, R. M. N. Capoeira nas aulas de Educação Física: uma proposta de intervenção. Pensar a Prática, Goiânia, v. 7, n. 2, p. 123-138, 2004.

OLIVEIRA, J. P. de; LEAL, L. A. P. Gênero, Cultura e Capoeiragem. In: OLIVEIRA, J. P. de; LEAL, L. A. P (org.). Capoeira, identidade e gênero: ensaios sobre a história social da capoeira no Brasil. Salvador: EDUFBA, 2009. p. 117-176.

OLIVEIRA, R. D. C. M. (Entre) Linhas de uma pesquisa: O Diário de Campo como dispositivo de (in) formação na/da abordagem (Auto) biográfica. Revista Brasileira de Educação de Jovens e Adultos, Salvador, v. 2, n. 4, p. 69-87, 2014.

PALHARES, L. R. Educação e cultura popular: inclusão social pela capoeira. Licere, Belo Horizonte, v. 10, n. 3, p.1-15, 2007.

PATTON, M. Q. Qualitative research and evaluative methods. 3. ed. California: Sage, 2002.

PEREIRA, L. de T. K.; GODOY, D. M. A.; TERÇARIOL, D. Estudo de caso como procedimento de pesquisa científica: reflexão a partir da clínica fonoaudiológica. Psicologia: Reflexão e Crítica, v. 22, n. 3, p. 422-429, 2009.

PINTO, F. M. Movimento/ Cultura popular: a luta continua camará. Motrivivência, Florianópolis, v. 22, n. 14, p. 115-132, 2000.

RESENDE, R. et al. Identidade profissional docente: influência do conhecimento profissional. In: QUEIRÓS, P.; BATISTA, P.; ROLIM, R. (ed.) Formação inicial de professores: reflexão e investigação da prática profissional. Porto: Editora FADEUP, 2014. p. 145-164.

et al. Exercício profissional do treinador desportivo: do conhecimento a uma competência eficaz. Journal of Sport Pedagogy and Research, Rio Maior, v. 3, n. 1, p. 42-58, 2017.

SAMPAIO, T. M. V.; TAVARES, L. C. V. A capoeira: nicho ecológico para repensar a concepção de jogo-educação. Licere, Belo Horizonte, v. 10, n. 2, p.1-19. 2007.

SANTA CATARINA. Lei complementar n. 495 de 26 de janeiro de 2010. Assembléia Legislativa do Estado de Santa Catarina, Florianópolis, 26 jan. 2010. Disponível em: http://leisestaduais.com.br/sc/lei-complementar-n-495-2010-santa-catarina-institui-asregioes-metropolitanas-de-florianopolis-do-vale-do-itajai-do-norte-nordeste- 
catarinense-de-lages-da-foz-do-rio-itajai-carbonifera-e-de-tubarao. Acesso em: 20 nov. 2020.

SANTIN, S. Educação física: da alegria do lúdico à opressão do rendimento. 2. ed. Porto Alegre: ESEF/UFRGS, 1996. 114 p.

SANTOS, G. de O. Alguns sentidos e significados da capoeira, da linguagem corporal, da Educação Física. Revista Brasileira de Ciências do Esporte, Campinas, v. 30, n. 2, p. 123-136, 2009.

SOUZA, E. G. R. da S. Capoeira: sua História e as Relações de Gênero. In: XIV Encontro Regional de História - ANPUH - Rio - Memória e Patrimônio, 2010, Rio de Janeiro. Anais [...] Rio de Janeiro, RJ: UNIRIO, 2010.

YIN, R. K. Case study research design and methods. 5. ed. Thousand Oaks: Sage, 2014. 282 p.

\section{Endereço das Autoras:}

Samara Escobar Martins

Estrada Bento Manoel Ferreira, 600 - Ratones

Florianópolis - SC - 88.052-300

Endereço Eletrônico: samara.escobaar@gmail.com

Maria Eduarda Tomaz Luiz

Rua Tupinambá, 710 - Jardim Atlântico,

Florianópolis - SC - 88.095-010

Endereço Eletrônico: maria_e.t.1@hotmail.com

Wihanna de Castro Cardozo Franzoni

Rua Fagundes Varela, 1187, bloco A, apto 1008 - Areais

São José - SC - 88.113-800

Endereço Eletrônico: hanna.franzoni@gmail.com

Lais Mendes Tavares

Servidão Papa João Paulo I,302 - Coqueiros

Florianópolis - SC - 88.080-310

Endereço Eletrônico: laismtavaress@gmail.com

Alcyane Marinho

Rua Vereador Filomeno, 357, Torre 1, apto 1001- Parque São Jorge

Florianópolis - SC - 88.034-495

Endereço Eletrônico: alcyane.marinho@hotmail.com 